$551.511 .6: 551.551 .8: 551.573$

\title{
A Numerical Study of the Air-Mass Transformation over the Japan Sea in Winter
}

\author{
By Tomio Asai* \\ Meteorological Research Institute, Tokyo \\ (Manuscript received 7 September 1964, in revised form 9 December 1964)
}

\begin{abstract}
One of the most important causes for snowfall over the Japanese Islands in winter is associated with the transformation of continental polar air-masses during passage over the Japan Sea. The cP air-masses are rapidly modified over the relatively warm water owing to the addition of sensible and latent heat. The theory of air-mass transformation due to eddy diffusions is re-examined by taking account of the phase change of water vapor and the variable exchange coefficient dependent on the static stability. Numerical experiments are made to test the model.

It is shown that the present simple model can describe the average weather condition over the Japan Sea in winter, if the variation of exchange coefficients in the model is taken into consideration.
\end{abstract}

\section{Introduction}

The northwest monsoon passing over the Japan Sea in winter is one of the most typical examples of the transformation of continental polar air-mass. This process is known to play an important role in the snowfall of the northwest coastal regions of the Japanese Islands. During passage over the Japan Sea, the cold air from Siberia receives a great deal of sensible heat and water vapor in its lower atmospheric layer.

Recently, some quantitative estimations of the heat supply were made, based on a heat and moisture budget analysis. An extensive network of surface and radiosonde observations stations in Japan, Korea and Siberia surrounding the Japan Sea were used for this purpose. Manabe (1957, 1958), first to investigate this problem, found that the amount of sensible heat supplied from the sea to the atmosphere is often as much as $1000 \mathrm{ly} \mathrm{day}^{-1}$ during the period of a typical outburst (for example, late Dec. 1954). It is much larger than the heat supplied by radiation or condensation. The sensible heat supplied from the sea averaged approximately $500 \mathrm{ly} \mathrm{day}^{-1}$

* Present address : National Center for Atmospheric Research, Boulder, Colorado, U.S.A. during the entire three months of winter (Dec. 1954-Feb. 1955). The amount of latent heat supplied through evaporation from the sea was estimated to reach about a half of the sensible heat supply. Manabe (1957) pointed out that the transport mechanism of heat may be different from that of water vapor in an unstable stratification as is observed over the Japan Sea in winter. The reason for this is that the Bowen ratio, which Manabe obtained, was remarkably larger than would be expected from the mixing length theory.

Recently, Ninomiya (1964) and Nakamura $(1964) * *$ evaluated these quantities along the line adopted by Manabe and obtained similar results. These results are summarized in Table 1. Ninomiya, in particular, performed

Table 1.

\begin{tabular}{lccl}
\hline \multicolumn{1}{c}{ Author } & $\begin{array}{c}\text { Sensible } \\
\text { heat } \\
\left(\text { ly day }^{-1}\right)\end{array}$ & $\begin{array}{c}\text { Latent } \\
\text { heat } \\
\left(\text { ly day }^{-1}\right)\end{array}$ & Remark \\
\hline Manabe (1957) & 1030 & 450 & outburst \\
Manabe (1958) & 555 & 340 & mean \\
Ninomiya (1964) & 1120 & 320 & heavy snow \\
Nakamura (1964) & 1000 & 500 & outburst \\
Kondo (1964) & & 495 & outburst \\
\hline
\end{tabular}

** Personal communication 
the budget analysis over both the Japan Sea and the Japanese Islands during 10 days (January 16-25, 1963) of heavy snowfall in the northwest coastal region of the Japanese Islands. Data obtained from the special radiosonde observations, gathered by a research project during heavy snowfall in the Hokuriku District, were added to the usual radiosonde data. It was shown that sensible heat supply increased remarkably in the situation in which a cold vortex was located over the Japan Sea. Furthermore, Ninomiya found that the liquid and/or solid states of water should be taken into account since the types of clouds formed over the Japan Sea affect seriously the snowfall in the northwest coastal region of the Japanese Islands.

The above investigations were based on the heat budget all over the Japan Sea. Kondo (1964), however, estimated the amount of evaporation from the Japan Sea by using his evaporation diagram and obtained the value of $495 \pm 55 \mathrm{ly} \mathrm{day}^{-1}$. This estimation was made for the period from 21 to 31 January of 1962 during which no cyclone passed through over the Sea.

On the other hand, Saito (1938), Arakawa (1940), Kurooka (1957) and others investigated how an air-mass is modified during the passage over the Japan Sea and attempted to explain some of the typical observed phenomena. Their explanations were based on the heat conduction theory applied first by Taylor (1915) to the study of an air-mass transformation off Newfoundland.

Takahashi (1940) criticized that in the above treatments the coefficients of eddy diffusion were assumed to be constant despite the fact that the magnitude of the coefficients depends strongly on the static stability. Burke (1945) employed an approach similar to Takahashi's in the study of air-mass transformation off the east coast of the United States.

In the present treatment, the exchange coefficients are assumed to be functions of the static stability and the phase change of moisture is taken into consideration. Our approach, however, differs from both Takahashi's and Burke's mentioned above.

\section{Brief review}

Taylor (1915) and many others studied air- mass transformation by applying the theory of heat conduction in a semi-infinite rod to the atmosphere. They solved the equation of heat conduction,

$$
\frac{\partial \theta}{\partial t}=K \frac{\partial^{2} \theta}{\partial z^{2}},
$$

under the following type of boundary and initial conditions.

$$
\begin{array}{ll}
\theta=\theta_{a}+\gamma z & \text { for } \quad z>0, t=0, \\
\theta=\theta_{s} & \text { for } \quad z=0, t \geq 0,
\end{array}
$$

where $\theta$ is the potential temperature, $K$ the coefficient of eddy conductivity and $\gamma \equiv \partial \theta / \partial z$ which is assumed to be constant. $\theta_{s}$ and $\theta_{a}$, respectively, denote the potential temperatures of water and air at the sea surface. $t$ and $z$ are time and vertical coordinate. The solution obtained is

$$
\theta=\theta_{a}+\gamma z+\left(\theta_{s}-\theta_{a}\right)\left\{1-E\left(\frac{z}{\sqrt{4 K t}}\right)\right\},
$$

where $E$ represents the error function, i.e.,

$$
E(\xi)=\frac{2}{\sqrt{\pi}} \int_{0}^{\xi} e^{-x^{2}} d x
$$

Let us define $z_{m}$ as the height at which the potential temperature, after a given time $t$, has increased by $\left(\theta_{s}-\theta_{a}\right) / 2$ and $t_{m}$ as the time after which $\theta$ has risen by $\left(\theta_{s}-\theta_{a}\right) / 2$ at a given level. According to Haurwitz (1941), there exists an approximate relationship between $z_{m}$ and $t_{m}$ that

$$
z_{m}=0.477 \sqrt{4 K t_{m}} .
$$

The heating effect spreads upwards rapidly within the lowest layer, and it proceeds slowly towards higher altitudes. When $K=1 \sim 10 \mathrm{~m}^{2}$ $\mathrm{sec}^{-1}$, for example, the height of mean heating $z_{m}$ after 1 day is of the order of several hundred meters. It requires approximately 5 days for $z_{m}$ to reach $0.7 \mathrm{~km}$ with $K=1 \mathrm{~m}^{2}$ $\mathrm{sec}^{-1}$ and $2 \mathrm{~km}$ with $K=10 \mathrm{~m}^{2} \mathrm{sec}^{-1}$. In this case, the sensible heat supplied from the sea surface during time period, $\tau$, can be approximated as follows

$$
H_{\tau}=2 C_{p} o\left(\theta_{s}-\theta_{a}\right) \sqrt{\frac{K \tau}{\pi}},
$$


where $C_{p}=0.24 \mathrm{cal} \mathrm{gr}^{-1}$, the specific heat of air at constant pressure, and $\rho=1.3 \times 10^{-3} \mathrm{gr}$ $\mathrm{cm}^{-3}$, the density of air. If we adopt $K=10$ $\mathrm{m}^{2} \mathrm{sec}^{-1}, \theta_{s}-\theta_{a}=10^{\circ} \mathrm{C}$ and $\tau=1$ day, $H_{\tau}$ becomes 325 ly day ${ }^{-1}$.

Priestley (1957) solved equation (2.1) under the following boundary condition to evaluate the heat flux at the surface. He assumed that the heat flux at the surface is proportional to the difference between air and surface temperatures and also to the surface wind speed i.e.,

$$
H_{0}=-\rho C_{p} C U\left(\theta_{a}-\theta_{s}\right) \text { at } z=0,
$$

and

$$
\theta=\theta_{i}+\gamma z \quad \text { at } t=0 .
$$

$\theta_{s}$ is the potential temperature of water at the surface and $\theta_{i}$ the potential temperature of the air close to the surface at $t=0 . \quad \theta_{a}$ and $U$ are the potential temperature of the air and the wind speed close to the surface respectively (approximately 10 meters altitude). $C$ is a constant coefficient. When $\theta_{s}$ is assumed to be constant, the solution is

$$
\begin{gathered}
\theta=\left(\theta_{i}-\frac{K \gamma}{C U}\right) \psi(\xi, \tau)+\gamma z+\frac{K \gamma}{C U}, \\
\phi(\xi, \tau)=E(\xi)+e^{2 \xi \tau+\tau^{2}}\{1-E(\xi+\tau)\},
\end{gathered}
$$

where $\xi=z / \sqrt{4 K t}$ and $\tau=C U \sqrt{t / K}$. The heat supply for 1 day is estimated to be $235 \mathrm{ly}$ for $C=0.0026, U=10 \mathrm{~m} \mathrm{sec}^{-1}, \theta_{s}-\theta_{i}=10^{\circ} \mathrm{C}$ and $K=10 \mathrm{~m}^{2} \mathrm{sec}^{-1}$. Even if $K$ increases to $10^{2} \mathrm{~m}^{2}$ $\mathrm{sec}^{-1}$, it would attain only $400 \mathrm{ly} \mathrm{day}^{-1}$. Therefore, an intense upward transfer of heat through a fairly deep layer would be expected over the Japan Sea during a certain period in winter. On the other hand, the continental polar air is usually characterized by a remarkable inversion in the lower layer which may be liable to prevent the formation of severe, tall convection. Hence the behavior of an inversion is studied simultaneously with the process of upward transfer of sensible and latent heat.

\section{Basic model for numerical experiment}

The classical theory of air-mass transformation due to the heat conduction will be improved by taking account of the effects of moisture and the variable eddy exchange coef- ficients which depend on static stability in the model.

In order to increase space resolution in the lower layer of the atmosphere, we introduce a new vertical coordinate, $Z$, which is similar to the special coordinate system proposed by Murakami (1964):

$$
Z=\left(\frac{z}{H}\right)^{1 / 2} .
$$

Here $H$ is assumed to be $8 \mathrm{~km}$ for convenience. The atmospheric layer with a depth of $8 \mathrm{~km}$ is divided into 20 sublayers, all being equal in $Z$. The geometrical height for each level and its corresponding pressure in the standard atmosphere are listed in Table 2.

Table 2. Conversion of coordinates.

\begin{tabular}{rlrr}
\hline$j$ & $Z$ & $z(\mathrm{~m})$ & $p(\mathrm{mb})$ \\
\hline 1 & 0 & 0 & 1,013 \\
2 & 0.05 & 20 & 1,011 \\
3 & 0.1 & 80 & 1,004 \\
4 & 0.15 & 180 & 993 \\
5 & 0.2 & 320 & 975 \\
6 & 0.25 & 500 & 955 \\
7 & 0.3 & 720 & 930 \\
8 & 0.35 & 980 & 901 \\
9 & 0.4 & 1,280 & 869 \\
10 & 0.45 & 1,620 & 833 \\
11 & 0.5 & 2,000 & 795 \\
12 & 0.55 & 2,420 & 754 \\
13 & 0.6 & 2,880 & 712 \\
14 & 0.65 & 3,380 & 667 \\
15 & 0.7 & 3,920 & 622 \\
16 & 0.75 & 4,500 & 577 \\
17 & 0.8 & 5,120 & 532 \\
18 & 0.85 & 5,780 & 486 \\
19 & 0.9 & 6,480 & 441 \\
20 & 0.95 & 7,220 & 397 \\
21 & 1 & 8,000 & 356 \\
\hline
\end{tabular}

If we assume a steady state of air flowing with a constant speed $U$ along the $x$-axis and neglect the horizontal diffusion, the following equations may be obtained,

$$
\begin{aligned}
& U \frac{\partial \theta}{\partial x}=\frac{1}{2 H Z} \frac{\partial}{\partial Z}\left(\frac{K_{\theta}}{2 H Z} \frac{\partial \theta}{\partial Z}\right)+Q, \\
& U \frac{\partial q}{\partial x}=\frac{1}{2 H Z} \frac{\partial}{\partial Z}\left(\frac{K_{q}}{2 H Z} \frac{\partial q}{\partial Z}\right)-M,
\end{aligned}
$$




$$
U \frac{\partial m}{\partial x}=\frac{1}{2 H Z} \frac{\partial}{\partial Z}\left(\frac{K_{m}}{2 H Z} \frac{\partial m}{\partial Z}\right)+M
$$

These equations govern the distribution of the potential temperature, $\theta$, the specific humidity $q$ and the liquid (solid) water content, $m$, respectively. $Q$ is the rate of heating due to condensation (sublimation) of water vapor. The negative value of $Q$ represents the rate of cooling due to the evaporation (sublimation) of liquid (solid) water. $M$ is the rate of condensation (sublimation). $K_{\theta}, K_{q}$ and $K_{m}$ denote the eddy exchange coefficients for sensible heat, water vapor and liquid (solid) water. We assume here, however, that $K_{\theta}=K_{q}=K$ and $K_{m}=0$.

The change, $\delta q_{s}$, of the saturation specific humidity $q_{s}$ following an air parcel moving horizontally can be expressed by that of $\theta$, $\delta \theta$, assuming an isobaric process, i.e.,

$$
\delta q_{s}=\frac{L}{R_{v}}\left(\frac{p_{0}}{p}\right)^{\kappa} \frac{q_{s}}{\theta^{2}} \delta \theta
$$

where $L$ is the latent heat of water vapor, $R_{v}$ the gas constant of water vapor, $p_{0}$ a reference pressure $(1000 \mathrm{mb})$ and $\kappa=\left(c_{p}-c_{v}\right) / c_{p}$ in which $c_{p}$ and $c_{v}$ denote the specific heats of air at constant pressure and volume, respectively. Here the saturation specific humidity $q_{s}$ is evaluated using the Tetens' empirical formula (1930), i.e.,

$$
q_{s}=3.8 \times 10^{\frac{a T}{T+b}} / p,
$$

where $T$ is the temperature in centigrade and $p$ the pressure in millibar. $a=7.5$ and $b=237.3$ over water, while $a=9.5$ and $b=265.5$ over ice.

The procedure for solving the set of the equations (3.2)-(3.5) is outlined below. The boundary conditions will be described in Section 4.

(i) First, the terms of $Q$ and $M$ are omitted from the equations (3.2)-(3.4), neglecting phase change of water substance. Then, $\theta$, $q, m$ and $q_{s}$ are computed tentatively, which are denoted by $\theta^{*}, q^{*}, m^{*}$ and $q_{s}^{*}$.

(ii) If $q^{*}-q_{s}^{*} \equiv \delta M>0$ (that is, if the air is over-saturated), $\delta M$ is divided into two parts. One is the condensed water $\delta M_{1}$, and the other is the increase of water vapor to be stored, $\delta M_{2}$. The warming due to condensation, $\delta \theta_{1}$, is

$$
\delta \theta_{1}=\frac{L}{c_{p}}\left(\frac{p_{0}}{p}\right)^{\kappa} \delta M_{1} .
$$

Then, $\delta M_{2}$ is obtained using Clapayron's law, as follows,

$$
\begin{aligned}
\delta M_{2} & =\frac{L}{R_{v}}\left(\frac{p_{0}}{p}\right)^{\kappa} \frac{q_{s}}{\theta^{2}} \delta \theta_{1} \\
& =\frac{L^{2}}{c_{p} R_{v}}\left(\frac{p_{0}}{p}\right)^{2 \kappa} \frac{q_{s}}{\theta^{2}} \delta M_{1} .
\end{aligned}
$$

Thus, the ratio $r_{1}$, of $\delta M_{1}$ to $\delta M\left(=\delta M_{1}+\delta M_{2}\right)$ is obtained as

$$
r_{1}=1 /\left\{1+\frac{L^{2}}{c_{p} R_{v}}\left(\frac{p_{0}}{p}\right)^{2 \kappa} \frac{q_{s}}{\theta^{2}}\right\} .
$$

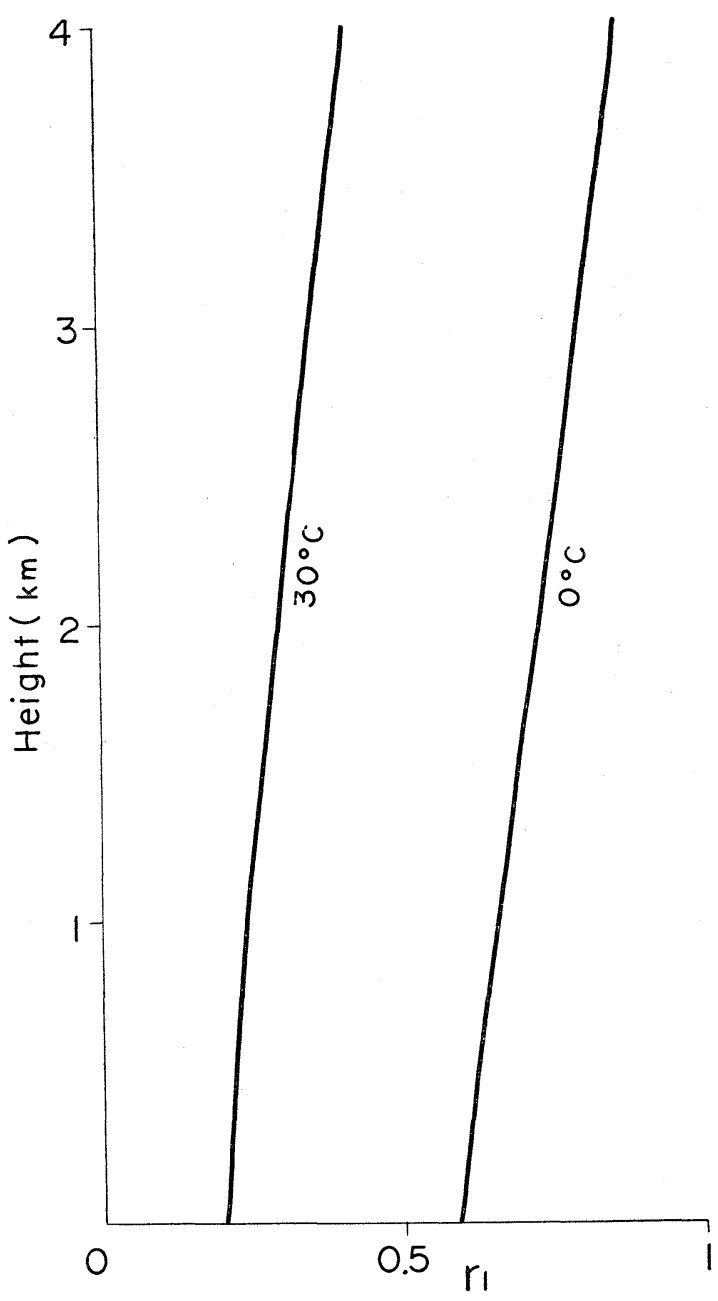

Fig. 1. The vertical distributions of the ratio, $r_{1}\left(\delta M_{1} / \delta M\right)$, for the surface temperature of $0^{\circ} \mathrm{C}$ and $30^{\circ} \mathrm{C}$, respectively, with the lapse rate of $6.5^{\circ} \mathrm{C} \mathrm{km}^{-1}$. 
The vertical distributions of $r_{1}$ in some cases are shown in Fig. 1 as a reference. $r_{1}$ increases with decreasing temperature and $\delta M_{1}$ becomes larger than $\partial M_{2}$ in the situation concerned here.

We then correct the tentative values, $\theta^{*}, q^{*}$, $m^{*}$ and $q_{s}{ }^{*}$ to those at a just-saturated state, as follows :

$$
\begin{aligned}
& \theta=\theta^{*}+\frac{L}{c_{p}}\left(\frac{p_{0}}{p}\right)^{\kappa} r_{1} \delta M, \\
& q=q^{*}-r_{1} \delta M, \\
& m=m^{*}+r_{1} \delta M, \\
& q_{s}=q .
\end{aligned}
$$

(iii) If $q^{*}-q_{s}{ }^{*} \equiv \delta M<0$ and $m^{*}>0$, evaporation should be expected. The maximum possible evaporation would be $-r_{1} \delta M$.

a) If $m^{*}+r_{1} \delta M \geq 0$, the evaporation attains the maximum possible value $-r_{1} \delta M$. Thus, the adjusted values of $\theta, q, m$ and $q_{s}$ can be computed from equations (3.10).

b) If $m^{*}+r_{1} \delta M<0$, the total amount of the existing liquid (solid) water $m^{*}$ should evaporate, and hence,

$$
\left.\begin{array}{l}
\theta=\theta^{*}-\frac{L}{c_{p}}\left(\frac{p_{0}}{p}\right)^{\kappa} m^{*}, \\
q=q^{*}+m^{*}, \\
m=0, \\
q_{s}=q_{s}^{*}-\frac{L^{2}}{c_{p} R_{v}}\left(\frac{p_{0}}{p}\right)^{2 \kappa} \frac{q_{s}^{*}}{\theta^{* 2}} m^{*} .
\end{array}\right\}
$$

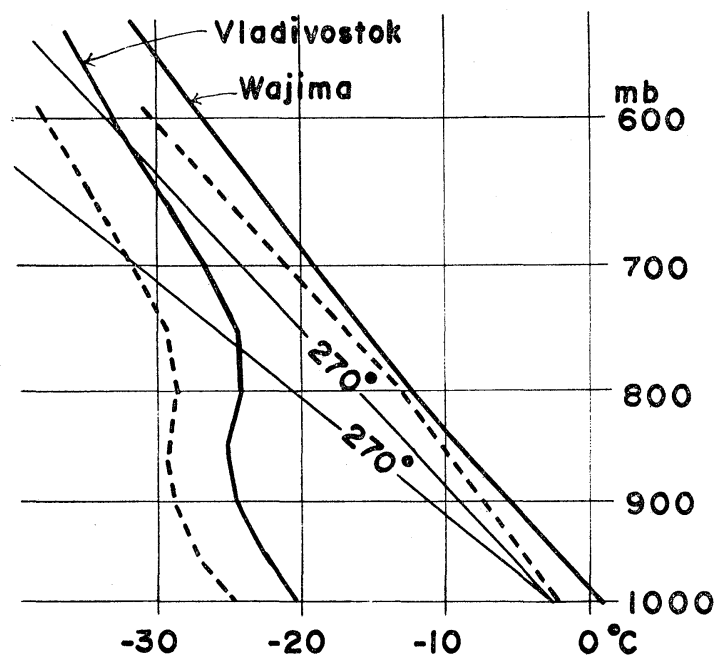

Fig. 3(a). Mean soundings at Vladivostok and Wajima during January 1963 . Solid lines denote temperature and broken lines dewpoint temperature. Thin slant lines are dry and moist adiabats of $270^{\circ} \mathrm{K}$, respectively. (iv) In the other cases, a correction to the tentative values obtained in (i) is not required.

\section{Boundary conditions}

We will adopt the atmospheric layer of $8 \mathrm{~km}$ in depth and $800 \mathrm{~km}$ in horizontal distance to approximate the fetch of the Japan Sea from Vladivostok in Siberia to Wajima in Japan as shown in Fig. 2.

The mean sounding at Vladivostok $P_{1}$, dur-

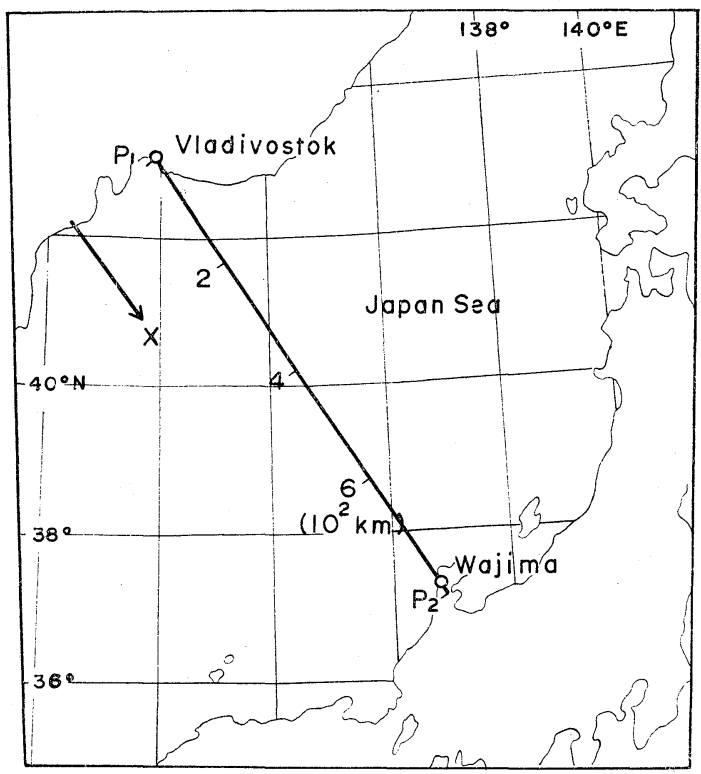

Fig. 2. The region to be considered for numerical experiment.

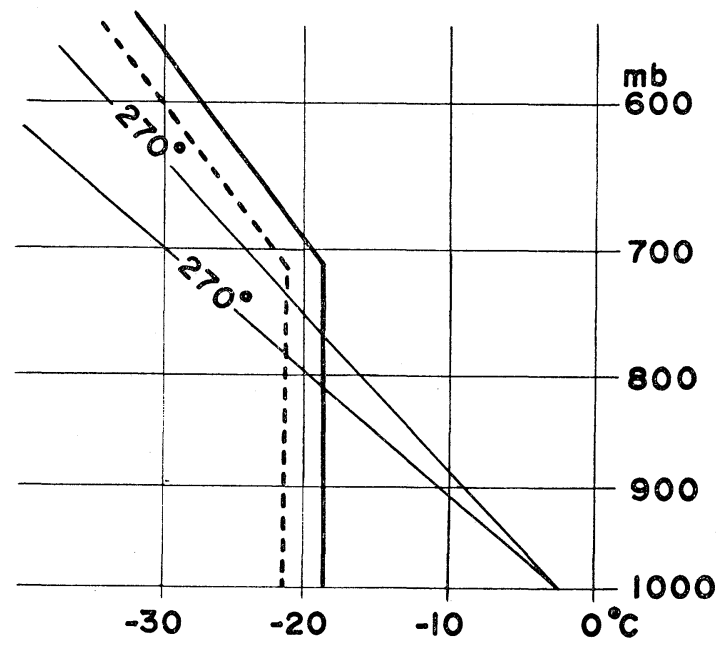

Fig. 3(b). Temperature and dew-point temperature profiles assumed at the point $P_{1}$ for experiment. 
ing January 1963 is illustrated in Fig. 3(a). The remarkable stable layer (inversion) ranging from 750 to $900 \mathrm{mb}$ level which may be the result of an extreme cooling in its low layer should be mentioned. The mean sounding at Wajima close to the terminal point $P_{2}$ during the same period is shown for comparison in Fig. 3(a). The inversion layer, which separates the lower moist unstable layer from the upper dry stable layer, is usually observed around the $800 \mathrm{mb}$ level at Wajima in winter. The inversion is not, however, as stationary nor noticeable as the one at Vladivostok, so that it may become indistinct on the average over a period of a month. The relative humidity around the $800 \mathrm{mb}$ level is almost always over $90 \%$ and a cloud layer exists there constantly. The condition assumed at the starting point, $x=0$, is shown in Fig. $3(\mathrm{~b})$. It is characterized by an isothermal layer (about $\left.-20^{\circ} \mathrm{C}\right)$ below around the $700 \mathrm{mb}$ level $(j=13)$ and by a constant lapse rate of $6.5^{\circ} \mathrm{C} \mathrm{km}^{-1}$ above. The relative humidity is assumed to be $80 \%$ throughout the whole layer. It should be noted that the air above around the $700 \mathrm{mb}$ level at Wajima was traced back westwards. Hence the temperature profile above the 700 mb level at the starting point was simulated using temperature soundings at Usan in the middle part of Korea.

Fig. 4 shows the distributions of the mean surface water temperature $T_{1}$ and the air temperature at the anemometer level $T_{2}$ from Vladivostok to Wajima. These temperature distributions are shown by broken lines for the period of 30 years and circles for the month of January 1963*.

The solid line shows the surface water temperature distribution used in the present experiment. The lower boundary conditions assumed here are prescribed by the fluxes of sensible heat and water vapor in the following forms,

$$
\left.\begin{array}{l}
F_{s}=\rho c_{p} C U\left(\theta_{1}-\theta_{2}\right), \\
F_{v}=\rho C U\left(q_{1}-q_{2}\right),
\end{array}\right\}
$$

where $\theta_{1}$ and $q_{1}$ denote the potential tempera-

* The data used have been provided by T. Fujita, Meteorological Research Institute in Tokyo. Fujita summarized the observational data by ships over the Japan Sea during January 1963.

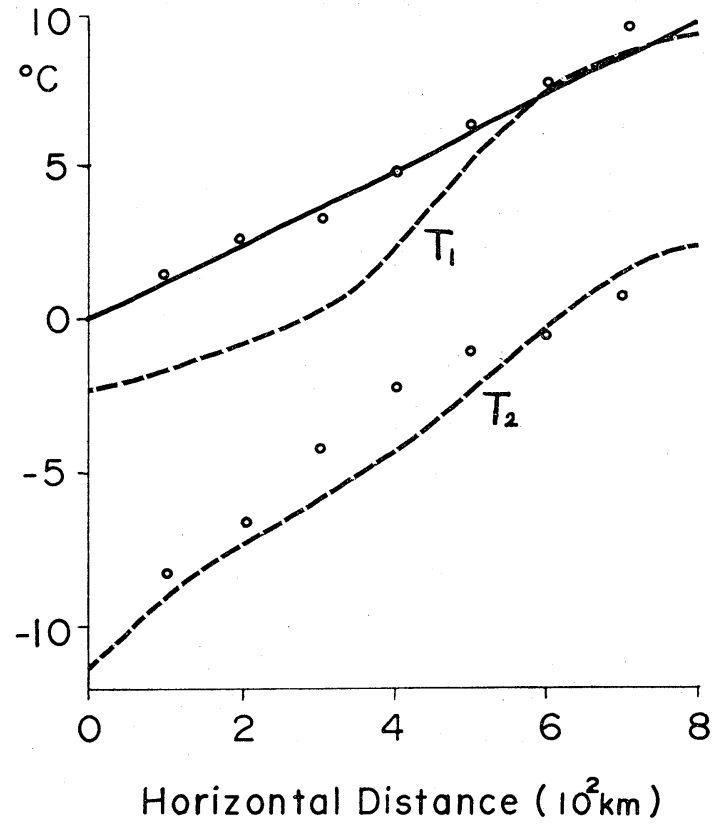

Fig. 4. Mean surface water temperature $\left(T_{1}\right)$ and air temperature at the anemometer level $\left(T_{2}\right)$ from Vladivostok to Wajima over the Japan Sea during 30 years are shown in broken line and those during January 1963 in circles. Solid line is the surface water temperature assumed for experiment.

ture and the saturation specific humidity at $Z=0$, while $\theta_{2}$ and $q_{2}$ represent the potential temperature and the specific humidity at $Z=$ $0.05 ; C$ is the transfer coefficient and is analogous to the drag coefficient. Deacon et. al.

Table 3. The cases used for numerical experiment $K=K^{*} /\{1+\alpha(\partial \theta / \partial z)\} . \quad K^{*}$ in $\mathrm{m}^{2} \mathrm{sec}^{-1}$ and $\alpha$ in $\mathrm{m}^{\circ} \mathrm{C}^{-1}$.

\begin{tabular}{|c|c|c|c|c|}
\hline Case & $C$ & $K^{*}$ & $\alpha$ & Remarks \\
\hline 1 & 0.0018 & 10 & 0 & $\begin{array}{l}\text { dry model without mois- } \\
\text { ture supply }\end{array}$ \\
\hline 2 & " & $"$ & $" \prime$ & \\
\hline 3 & $" \prime$ & 1 & $"$ & \\
\hline 4 & $" 1$ & 50 & " & \\
\hline 5 & 0.0026 & 10 & " & \\
\hline 6 & 0.0036 & $" \prime$ & $" 1$ & \\
\hline 7 & 0.0018 & $" \prime$ & $10^{2}$ & variable $K$ below this case \\
\hline 8 & " & " & $5 \times 12^{2}$ & \\
\hline 9 & 0.0026 & $" \prime$ & $10^{2}$ & \\
\hline 10 & 0.0018 & $" \prime$ & $" \prime$ & relative humidity of $20 \%$ \\
\hline 11 & " & " & $" \prime$ & top of inversion at $j=10$ \\
\hline 12 & $\prime \prime$ & $"$ & $"$ & sublimation occurred \\
\hline
\end{tabular}


(1956) obtained the drag coefficient ranging from 0.001 to 0.003 under the condition of $U=$ $10 \mathrm{~m} \mathrm{sec}^{-1}$ at $10 \mathrm{~m}$ above the sea surface in the neutral stratification. Jacobs (1942) found $C=$ 0.0022 from the calculation of energy balance over the major oceans using climatological data. At the upper boundary, $Z=1$, no fluxes of sensible heat and water vapor are assumed.

The following 12 cases were studied for various values of $C$ and $K$ as listed in Table 3 .

\section{A check of computation}

We adopt the forward difference method (along the direction of flow) for equations (3.2)

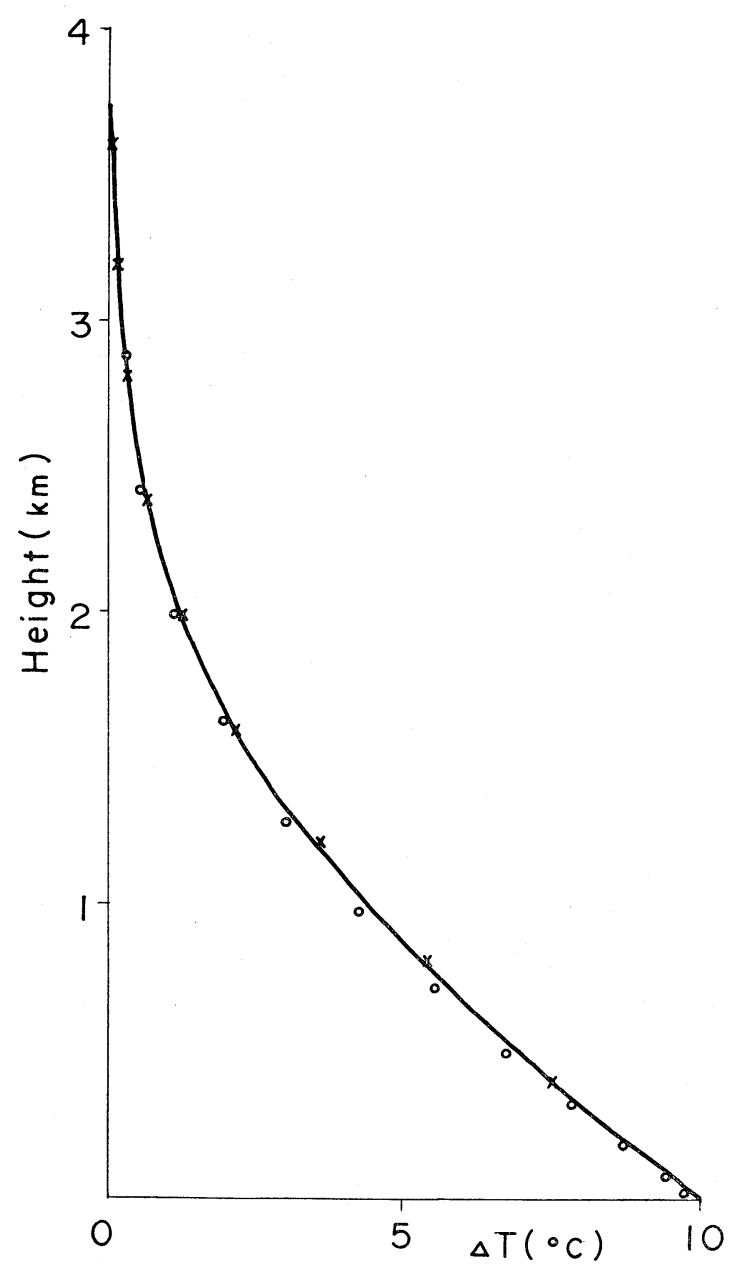

Fig. 5. Solid line shows the exact solution which represents the vertical profile of temperature increase at the terminal point. Crosses and circles denote the corresponding solutions obtained by numerical integration in $z$ and $Z$ coordinates, respectively.
-(3.4). The space difference $\Delta x$ necessary to satisfy the computational stability criterion should be taken as follows (Richtmyer, 1957),

$$
\Delta x<\frac{U_{\min }\left(2 H \Delta Z \cdot Z_{\min }\right)^{2}}{2 K_{\max }}
$$

If we assume the minimum value of $U, U_{\min }$ $=10 \mathrm{~m} \mathrm{sec}^{-1}$ and the maximum value of $K$, $K_{\max }=10 \mathrm{~m}^{2} \mathrm{sec}^{-1}$, then

$$
\Delta x<800 \mathrm{~m},
$$

for $H=8 \mathrm{~km}, \Delta Z=0.05$ and $Z_{\min }=0.05$.

As mentioned in Section 2, equation (2.1) with a constant exchange coefficient has been solved analytically under the boundary condition (2.2) and the initial condition (2.3). Hence, the exact solution (2.4) is used to check the accuracy of the present method of numerical integration. Fig. 5 illustrates the vertical distribution of the temperature increase $\Delta T$ at $800 \mathrm{~km}$ downwind from that at the starting point. The exact solution is illustrated by the solid line. Crosses and circles show the approximate solutions obtained by the numerical integration on the basis of the $z$ coordinate, in which 400 meters is used for $\Delta z$, and the $Z$ coordinate, respecitvely. Here we assumed that $U=10 \mathrm{~m} \mathrm{sec}-1, K=10 \mathrm{~m}^{2} \mathrm{sec}^{-1}$ and the difference between water and air temperatures at the sea surface is $10^{\circ} \mathrm{C}$. The agreement between the numerical solutions obtained in both coordinate systems and the exact solution is very good.

\section{Results of calculations}

We will discuss the major results obtained from the 12 cases listed in Table 3 . For convenience, the results are shown by converting potential temperature $\theta$ into temperature $T$.

\section{(1) Inclusion of moisture}

Fig. 6 shows the vertical distributions of temperature increases at the terminal point for cases 1 and 2, and of water vapor increase, liquid water content and relative humidity for case 2. The cloud layer may be observed between the altitudes from 300 to 1000 meters, and the total amount of liquid water in the cloud layer was $0.44 \mathrm{~mm}$. On the other hand, the amounts of water vapor and sensible heat supplied from the sea were $4.3 \mathrm{~mm}$ (2501y) and 340 ly, respectively. This indicates that only 


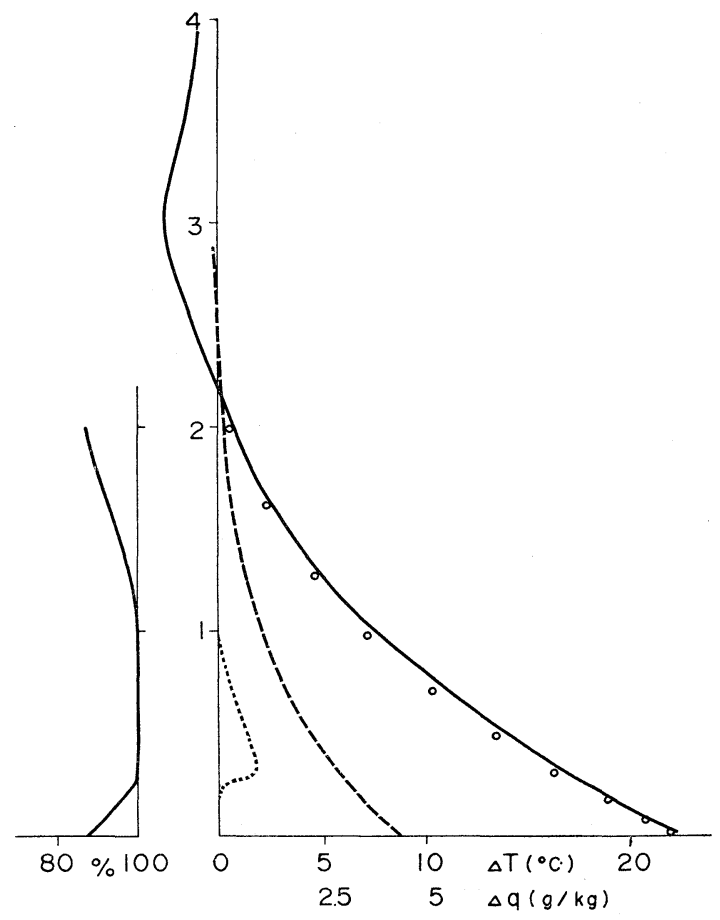

Fig. 6. Vertical profiles of temperature increases (solid line in case 2, circles in case 1), water vapor increase (broken line), liquid water content (dotted line) and relative humidity (solid line on the left side) at the terminal point, respectively.

$10 \%$ of the water vapor supplied from the sea is consumed by the condensation and the remaining $90 \%$ is stored in the form of vapor, since the remarkable warming concurrently occurs owing to a great amount of sensible heat supply. Inclusion of water vapor in case 2 contributed to increase the temperature of the lower part of the atmosphere by only $0.5^{\circ} \mathrm{C}$ compared with case 1 . Although the amount of condensed water increases much more in other cases as shown below, the direct influence of condensation through eddy exchange mechanism considered here may be rather slight upon the temperature field.

(2) Constant exchange coefficient

The dependence of air-mass transformation on the magnitude of exchange coefficient $K$ is shown in Fig. 7(a). As is expected, the rate of transformation becomes more effective as the coefficient increases. In other words, the initial inversion layer was destroyed only below $800 \mathrm{~m}$ in case 3 . However, the inversion has almost disappeared for $K=50 \mathrm{~m}^{2} \mathrm{sec}^{-1}$.
The sensible heat supply, however, does not necessarily increase with increasing $K$. It is shown in Fig. 7 (c) that the sensible heat supply in case 4 only attains a value of about $3001 \mathrm{y}$. This value is a little smaller (by $30 \mathrm{ly}$ ) than that in case 2. The increase of $K$ above a certain value did not contribute to increase the sensible heat supply unless the other conditions, such as the magnitude of transfer coefficient at the sea surface, were changed. The reason for this is due to: (i) less upward heat transport in the low layer resulting from rapid formation of neutral stratification and, (ii) the increase in the downward transport in the stable upper layer with an increase of $K$. Hence, the surface air temperature in the lowest level tends to approach the surface water temperature and the sensible heat supply decreases (Fig. $7(\mathrm{~b})$ ).

We should notice that no cloud layer is found in case 4 with the exception of the saturation in the uppermost layers due to the fictitious boundary condition, that is, no flux of entities is assumed at the upper boundary. Thus, the assumption of a constant exchange coefficient seems to bring on an unrealistic result.

(3) Transfer coefficient at the lower boundary

Here we took three different constants for the transfer coefficient at the lower boundary, $C$, for the same value of exchange coefficient, $K=10 \mathrm{~m}^{2} \mathrm{sec}^{-1}$. The results of those are illustrated in Fig. 8(a), (b) and (c). The amounts of sensible and latent heat supply and the profiles of temperature and moisture in case 2 , are not so different from those for cases 5 and 6 in which $C=0.0026$ and $C=0.0036$, respectively, were used as coefficients. It is indicated in Fig. 8(c) that the supply of both sensible and latent heat increases only by about $20 \%$ as the magnitude of the coefficient doubles. This is easily understood from Fig. 8(b) which shows both the temperature and the specific humidity in the lowest level approaching those of the sea surface as the transfer coefficient increases. Therefore the increase of transfer coefficient at the lower boundary is not so effective in increasing heat supply from the sea, unless it is associated with an appropriate increase of upward heat transport in the upper layer adjacent to the boundary layer. This is indicated clearly below. 

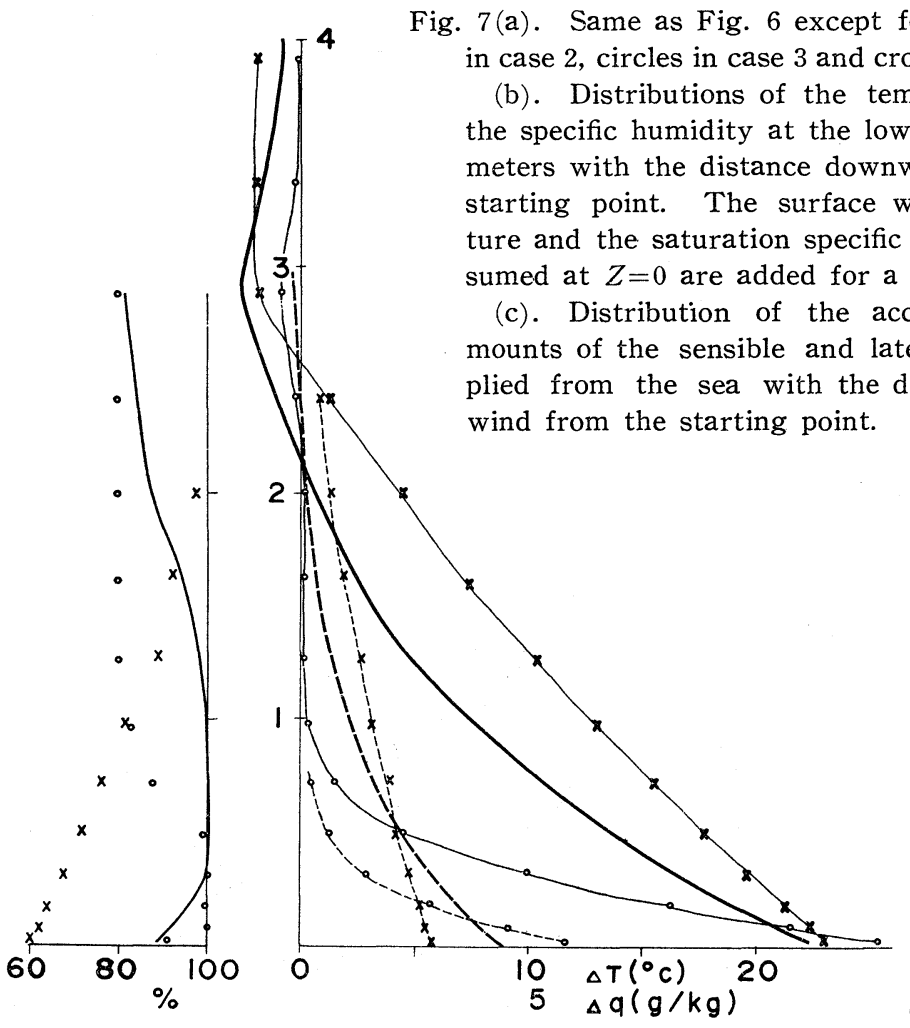

(a)
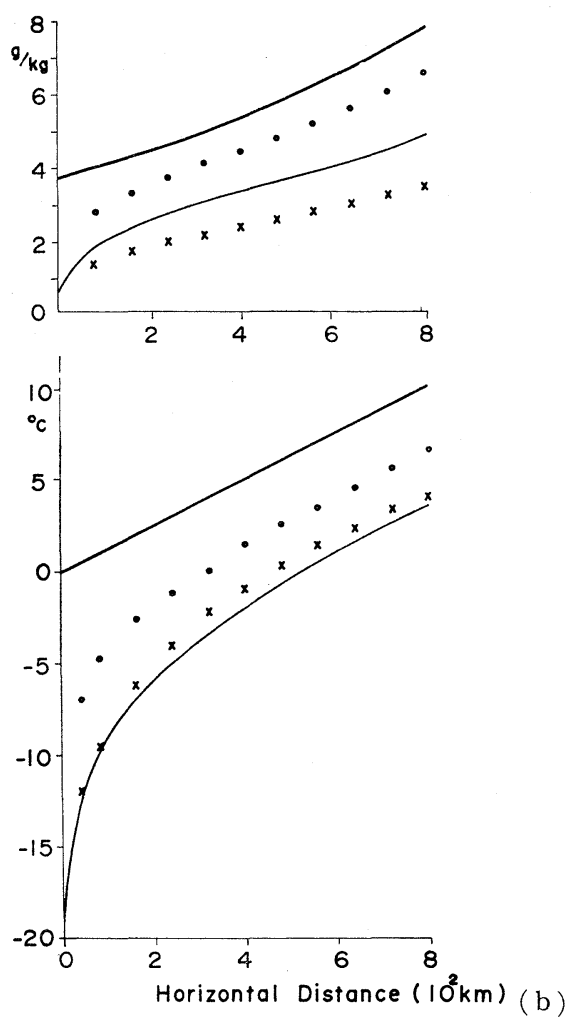

Latent Heat

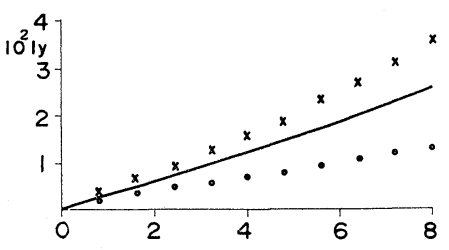

Sensible Heat

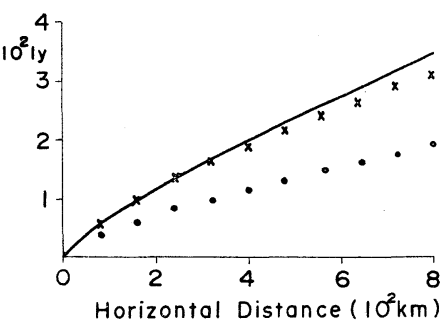

(c) 

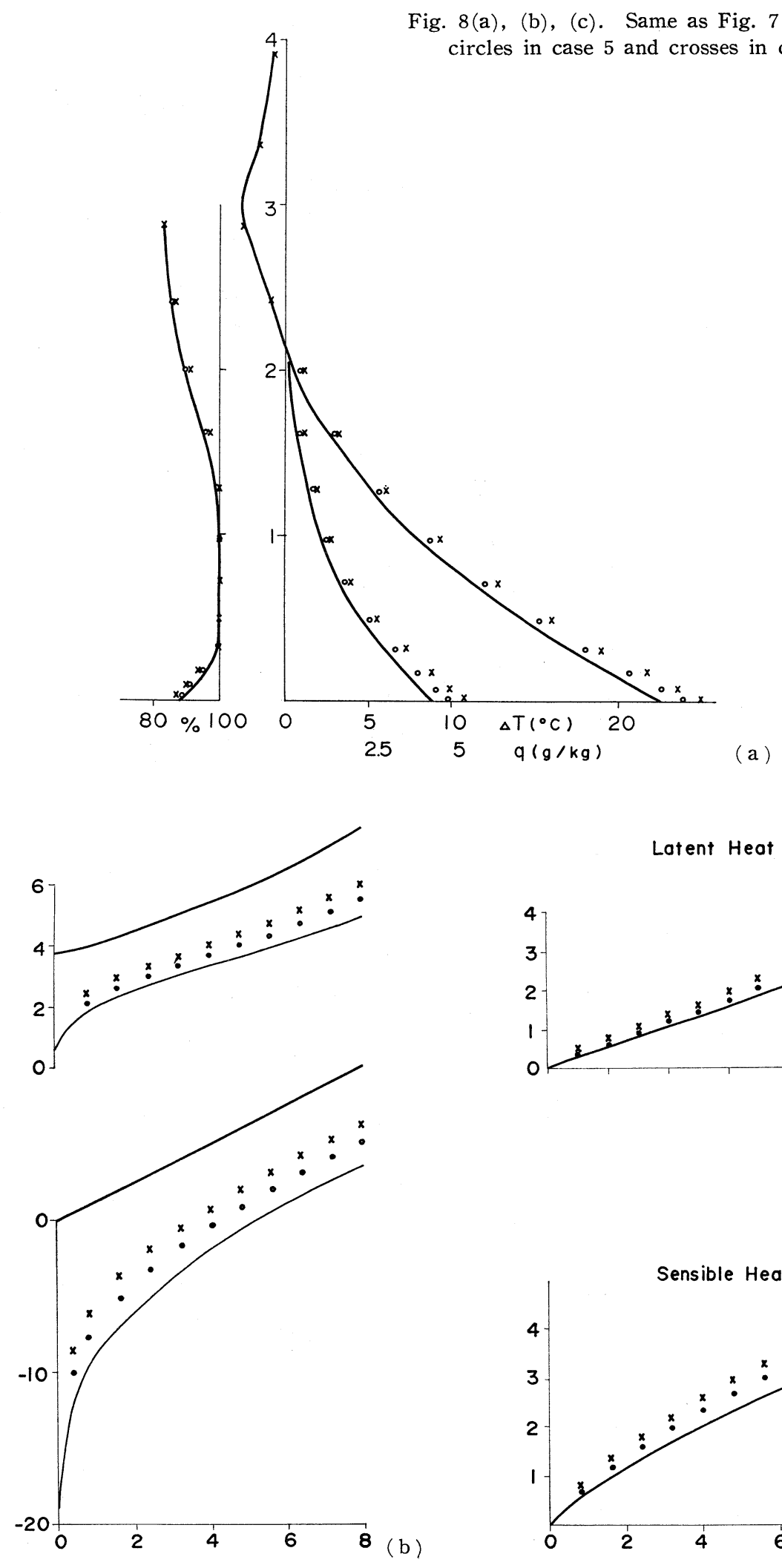

Latent Heat
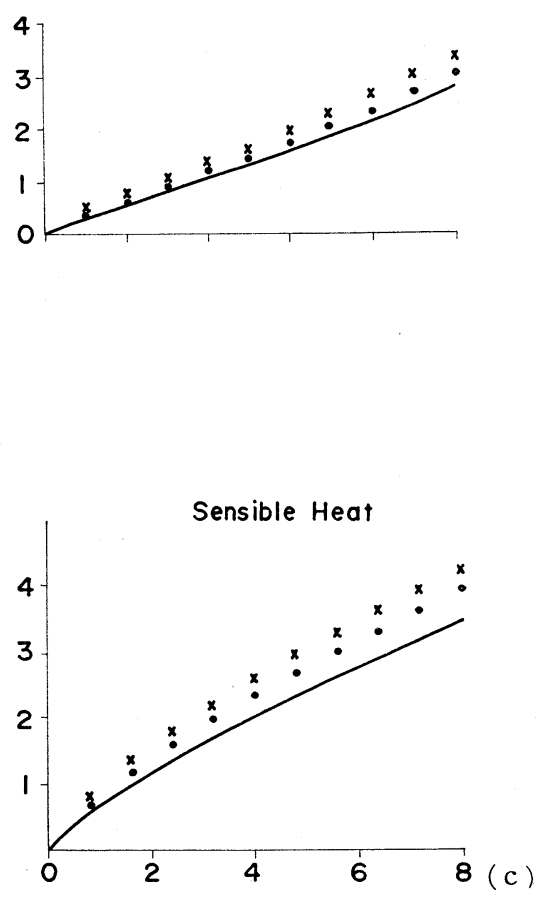
Fig. 9(a), (b), (c). Same as Fig. 7 except
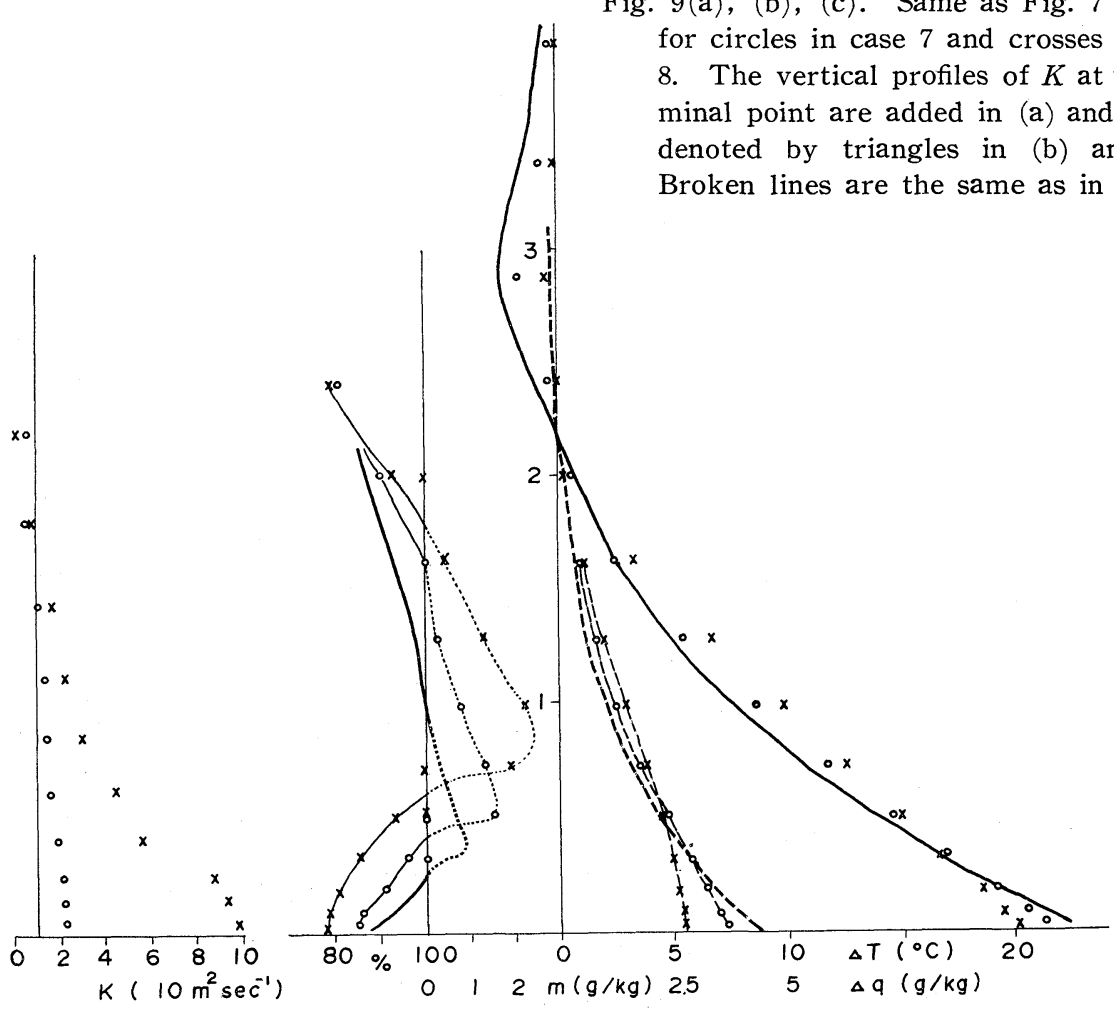

(a)
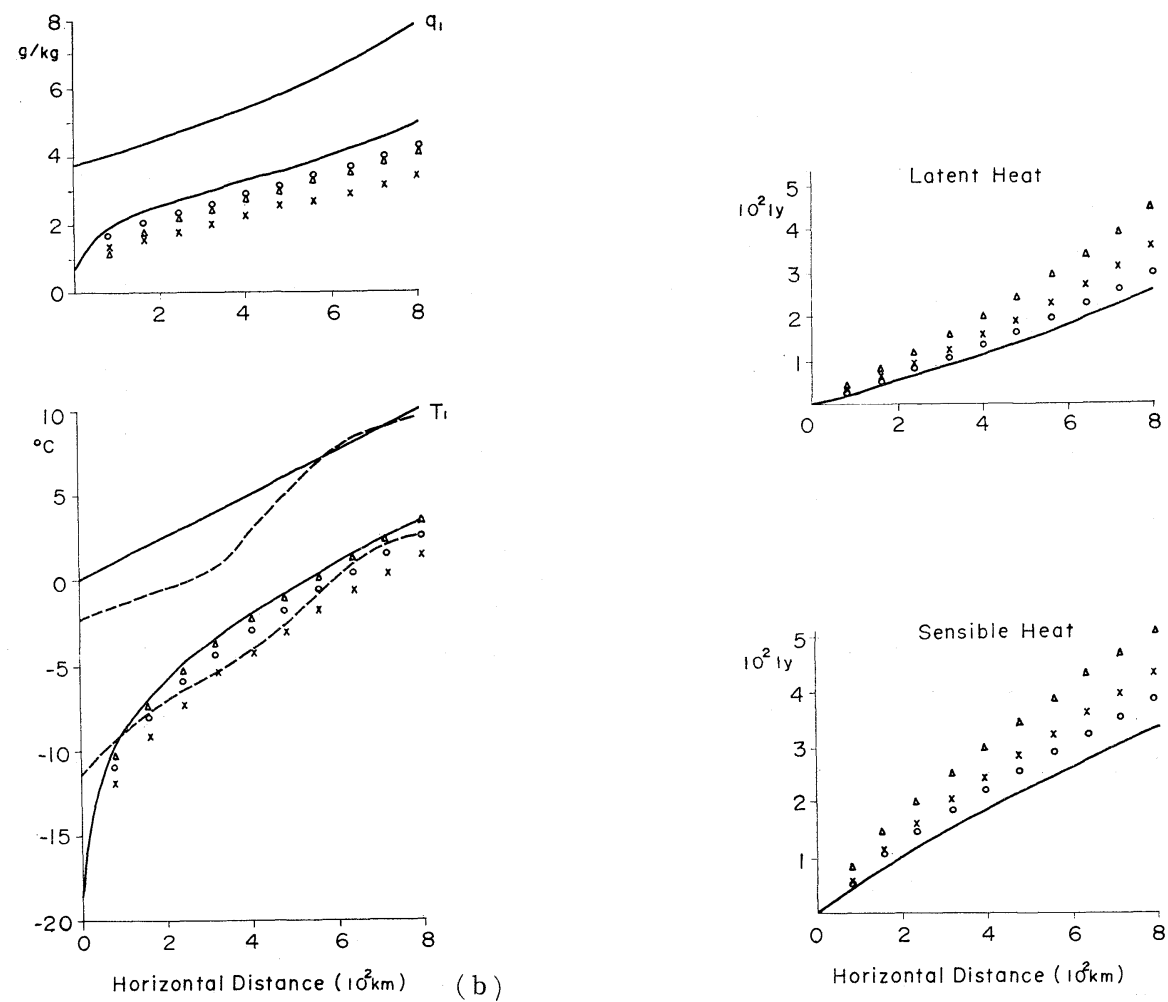

(c) 
The assumption that $C$ and $K$ are independent of each other may possibly become one weakness in the present model.

(4) Variable exchange coefficient

The coefficient of eddy exchange $K$ is assumed to depend only upon the static stability in the following form,

$$
K=\frac{K^{*}}{1+\alpha \frac{\partial \theta}{\partial z}}=\frac{K^{*}}{1+\frac{\alpha}{2 H Z} \frac{\partial \theta}{\partial Z}}
$$

The relation (6.1) was derived empirically by Takahashi (1963)**. It implies only that $K$ increases with decreasing stability and decreases with increasing stability. This is similar to the expression, $K=K^{*} \exp (-\alpha(\partial \theta / \partial z))$ adopted by Fisher and Caplan (1963) in the prediction model of fog. $K^{*}$ is the exchange coefficient which might be expected under adiabatic conditions and is prescribed to be $10 \mathrm{~m}^{2} \mathrm{sec}^{-1}$ here. $\alpha$ is assumed to be $10^{2} \mathrm{~m}^{\circ} \mathrm{C}^{-1}$ except that in case 8 , it is assumed to be 5 $\times 10^{2} \mathrm{~m}^{\circ} \mathrm{C}^{-1}$.

The vertical profiles of temperature and moisture at the terminal point $P_{2}$ are shown in Fig. 9(a) for cases 2, 7 and 8, respectively. Cases 7 and 8 are compared with case 2. In the former cases, the exchange coefficients depend to a variable degree on the static stability as contrasted with case 2 in which there is a constant exchange coefficient. The increases in temperature and moisture in cases 7 and 8 are less in the layer below the 200 meter level and greater in the higher layer when compared with case 2.

Cases 7 and 8 are characterized by the presence of deeper cloud layers with higher bases. These cloud layers have the liquid water content amounting to 1.0 and $1.9 \mathrm{~mm}$, respectively. They acquire 20 and $30 \%$ of the water vapor supplied, respectively. If the liquid water content is reduced by one half as the clouds move through the distance of $100 \mathrm{~km}$ downwind from the point $P_{2}$, the amount of precipitation occurring would be about 4 and $8 \mathrm{~mm}$ per day in cases 7 and 8 , respectively. These amounts of cloud and precipitation expected may be fairly realistic during the period of moderate cold air outbursts.

In addition to the increase of sensible and

\footnotetext{
** Personal communication.
}

latent heat supplies in the cases with variable exchange coefficients, we should notice a remarkable increase of them in case 9. This is shown by triangles in Fig. 9(c). The sensible and latent heat supplies in case 5 increase only 45 and $25 \mathrm{ly} \mathrm{day}{ }^{-1}$, more than those in case 2 , respectively. These cases are compared under conditions of the same constant exchange coefficient. Their increases attain 120 and $150 \mathrm{ly}$ day $^{-1}$, respectively under conditions of a variable exchange coefficient (compared case 9 with case 7 ). It is thus suggested that the increase of transfer coefficient $C$ is very effective in increasing the heat supplied from the sea when associated with an appropriate increase of exchange coefficient in the layer adjacent to the boundary layer.

In each case of experiment, the difference between the surface water temperature and the lowest level air temperature is assumed to be about $20^{\circ} \mathrm{C}$ at the starting point. This temperature difference decreases rapidly to a half of its original value before arriving at a point $100 \mathrm{~km}$ downwind. The difference then becomes constant after the air reaches a point $200 \mathrm{~km}$ downwind. As for the water vapor, the corresponding difference in the values of specific humidities tends to increase with the distance from $100 \mathrm{~km}$ downwind (Fig. 9(b)).

The stratification which might be expected at the terminal point in case 8 is shown in Fig. 10. The inversion layer in the model did not disappear in each case except for the

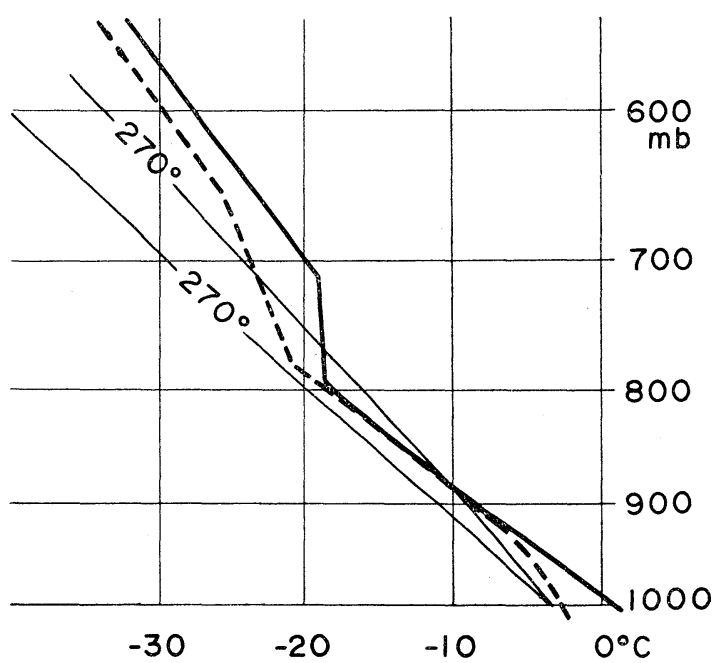

Fig. 10. Sounding to be expected at the terminal point in case 8 . 


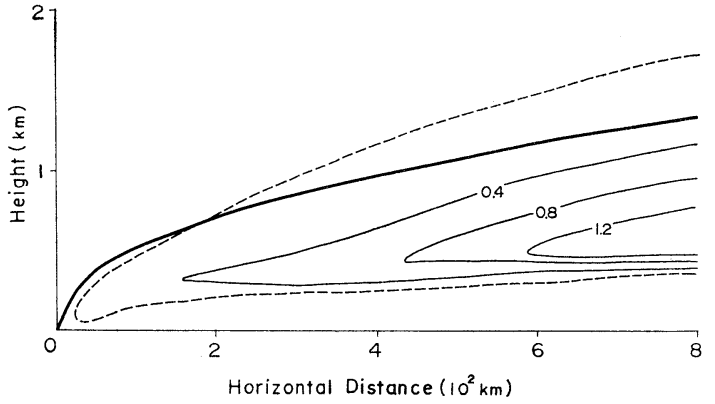

(a)

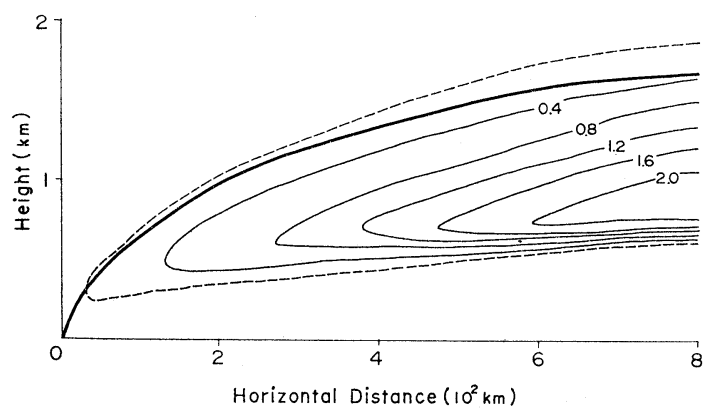

(b)

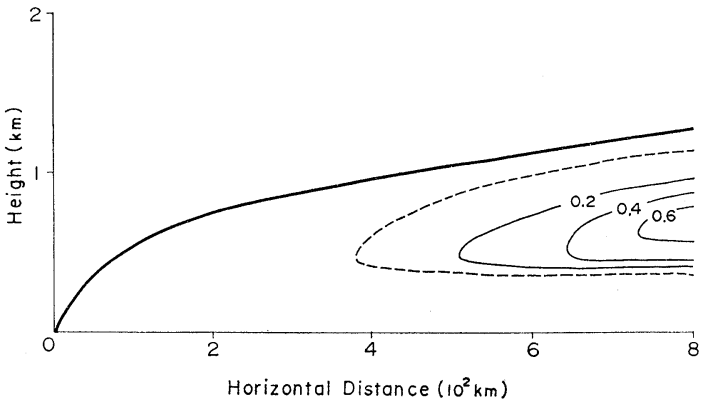

(c)

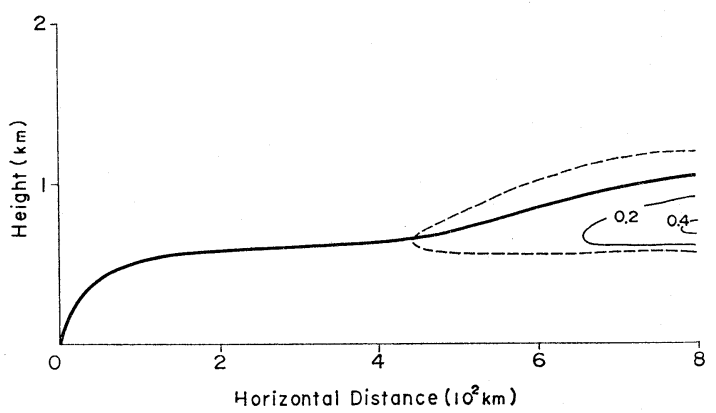

(d)

Fig. 11. Cross sections in the vertical plane along the wind from $P_{1}$ to $P_{2}$. Solid lines show liquid water content in $\mathrm{g} \mathrm{kg}^{-1}$, broken lines cloud layers and thick solid lines the top of unstable layer. (a) is for case 7, (b) for case 8, (c) for case 10 and (d) for case 11 .

use of an abnormally large magnitude for the exchange coefficient. Usually, an inversion layer is observed around the $800 \mathrm{mb}$ level over the Japanese Islands, although it often disappears during the period of heavy snowfall.

Fig. 11 shows the distributions of cloud layer (bounded by a broken line), liquid water content (solid line, $\mathrm{g} / \mathrm{kg}$ ) and the top of unstable layer (or the base of inversion). This diagram is made in the vertical plane along the wind from $P_{1}$ to $P_{2}$. In cases 7 and 8 (illustrated in Figs. 11 (a) and (b), respectively), clouds form in the restricted low layer immediately after leaving the point $P_{1}$ and then the top and the thickness of the clound layer gradually increase downwind. The cloud top reaches the 1800 meter level at the terminal point where the cloud extends into the stable layer by several hundred meters. It may be seen from Figs. 11(c) and (d) that the origin of the cloud with respect to the starting point depends on the humidity of the initial airmass and the temperature difference between the surface water and air. In case 10, with extremely dry air having a relative humidity of $20 \%$, clouds form around $400 \mathrm{~km}$ downwind from the point $P_{1}$. Since an air layer with relative humidity of $50 \sim 60 \%$ is most often observed around Vladivostok, we can expect a cloud formation to be observed as far as central parts of the Japan Sea. In case 11, with a rather small difference between the surface water and air temperatures, clouds are found at the distance of $500 \mathrm{~km}$ from the point $P_{1}$. This condition would correspond to a situation over a continent where the polar air undergoes less cooling. In both cases 10 and 11, however, only small amounts of liquid water are contained in the thin cloud layers below approximately 1000 meters. These quantities would be 0.37 and $0.16 \mathrm{~mm}$, respectively. Hence, the precipitation to be expected is too little.

Case 12, in which sublimation is assumed to occur, is little different from case 7 except for a small increase of water content in the present model. 


\section{Concluding remarks}

It was shown in this paper that the diffusion model with a constant exchange coefficient fails to explain consistently phenomena of air mass transformation over the Japan Sea in winter. As far as moderate weather conditions are concerned, the revised diffusion model can simulate the characteristics of the thermal and moisture patterns and of energy exchange over the Sea. On the other hand, the present model will encounter serious problems which will remain unsolved when this model is applied for severe weather conditions. During this period, a number of cumulus and cumulonimbus, sometimes with thunder, have already formed over the Japan Sea and are often reported to reach the $6 \mathrm{~km}$ level or so. As suggested in Section 6, we may have to take into account the intense upward heat transport due to cumulus convection in the free atmosphere together with smaller scale eddy transport processes in the boundary and subcloud layers in the air-mass transformation.

In addition, a cumulus convection, especial1y tall cumulonimbus, will generally not develop in the cold season without the heat and moisture from outside of the system (for example, Asai (1964)). In the present case, howèver, we can expect a great deal of heat supply from the lower boundary and subcloud layers which also depends on the activity of cumulus convection in the upper layer. Another more important matter to be considered is the influence of larger scale atmospheric situations on the cumulus convection. Based on the synoptic analysis during the heavy snowfall period in January 1963, the cold cyclonic vortex observed typically in the middle level of the atmosphere over the Japan Sea was indicated to be associated with a heavy snowfall in the Japanese Islands (Matsumoto et al (1964) and Ninomiya (1964)). This situation may provide less stable stratification through deep layers and general upward motion associated with the horizontal convergence in the low layer.

\section{Acknowledgment}

The author wishes to express his sincere thanks to Dr. K. Takahashi and Dr. S. Matsumoto for their kind guidance and encourage- ment throughout this work. He is indebted to Dr. A. Kasahara, National Center for Atmospheric Research, U.S.A., for revising the manuscript.

\section{References}

Arakawa, H., 1940 : Zur Bildung der Cunb-Wolken in der Kaltluftmasse und zur Bildung und insbesondere Erhaltung des Nebels in der Warmluftmasse. J. meteor. Soc. Japan, Ser. II, 18, $81-84$.

Asai, T., 1964: Numerical experiment of cumulus convection under the pseudo-adiabatic process. Papers in Meteor. and Geophys., 15, 1-30.

Burke, C.J., 1945: Transformation of polar continental air to polar maritime air. J. Meteor. 2, 94-112.

Deacon, E.L., P.A. Sheppard and E.K. Webb., 1956 : Wind profiles over the sea and the drag at sea surface. Australian J. Physics, 9, 511-541.

Fisher, E.L. and P. Caplan, 1963: An experiment in numerical prediction of fog and stratus. $J$. Atmos. Sci., 20, 425-437.

Haurwitz, B., 1941: Dynamic Meteorology. McGraw-Hill Book Company, Inc , 226-231.

Jacobs, W.C., 1942: On the energy exchange between sea and atmosphere. J. Marine Res., 5, $37-66$.

Kondo, J., 1964: Evaporation from the Japan Sea in the winter monsoon season. Sci. Rep. Tohoku Univ., Ser. 5, Geophys., 15, 67-75.

Kurooka, H., 1957: Modification of Siberian airmass caused by flowing out over the open sea surface of northern Japan. J. meteor. Soc. Japan, Ser. II., 35, 52-59.

Manabe, S., 1957: On the modification of air-mass over the Japan Sea when the outburst of cold air predominates. J. meteor. Soc. Japan, Ser. II. 35, 311-326.

, 1958: On the estimation of energy exchange between the Japan Sea and the atmosphere during winter based upon the energy budget of both the atmosphere and the sea. $J$. meteor. Soc. Japan, Ser. II 36, 123-134.

Matsumoto, S., T. Asai, K. Ninomiya, M. Iida and M. Takeuchi, 1964: Behavior of the extraordinary cold vortex over the Far East coastal area observed during the period from Jan. 22 to Jan. 24, 1963. To be published.

Murakami, T., 1964: Multiple-level model for the $p$ - and $s$-coordinates. J. meteor. Soc. Japan, Ser. II. 42, 1-13.

Ninomiya, K., 1964: Heat budget over the Japan Sea and the Japan Islands during the period of heavy snow storm. Papers in Meteor. and Geophys., 15, 52-70. 
, 1964: Water substance budget over the Japan Sea and the Japan Islands during the period of heavy snow storm. J. meteor. Soc. Japan, Ser. II, 42, 317-329.

Priestley, C.H.B., 1957: The evolution of energy gain by the atmosphere through contact with the ground or ocean. Scientific Report, No. 2, Dept. Meteor., Chicago Univ., 1-56.

Richtmyer, R.D., 1957: Difference methods for initial value problems. Interscience Publishers,
Inc., New York, 238 pp.

Saito, H., 1938: On the theory of cloud-formation in winter monsoon field. J. meteor. Soc. Japan, Ser. II. 16, 28-34.

Takahashi, K., 1940: On the transformation of the cold and dry air-mass by traveling over warm sea. J. meteor. Soc. Japan, Ser. II. 18, 77-80.

Taylor, G.I., 1915 : Eddy motion in the atmosphere. Phil. Trans. Roy. Soc. (London) A, 215, 1-26.

\title{
冬期日本海上における気団変質についての数値実験
}

\author{
浅井冨 雄* \\ 気象研究所
}

\begin{abstract}
大陸極気団が䁔かい日本海上を吹送する間に海面から顕熱・潜熱の補給を受けて变質する過程は冬期裏日本と扮け る降雪の重要な原因の一つである。

ここでは, 渦拡散論に基づく既存の気団変質論飞, 水蒸気の相变化と, 静的安定度に依存する渦拡散係数の可变性 を考虑に入れて拡張した若干のモデルとついて数值解を求め, その結果を検討した。

冬期日本海上での気団变質—海面から熱・水蒸気の補給, それらの大気中での分布, 水蒸気の一部凝結等—を 説明することは, 一定係数の渦拡散論では困難であるが, 安定度に伴って変化する渦拡散係数を用いれば少くとも冬 期の平均状態関する限り可能であることが示される。
\end{abstract}

* 現在：国立大気研究センター，米国コロラド州ボルダー 